\title{
RECURSIVE LEAST SQUARE ALGORITHM FOR ESTIMATING PARAMETERS OF AN INDUCTION MOTOR
}

\author{
Yehia S. Mohamed \\ Electrical Engineering Department, Minia Uni., Egypt
}

B. M. Hasaneen

Department of Electrical Power and Machine, Alazhar Uni., Qena, Egypt

\section{Adel A. Elbaset}

Electrical Engineering Department, Minia Uni., Egypt

\section{Alaa Eldin Hussein}

Department of Electrical Power and Machine, Alazhar Uni., Qena, Egypt

(Received October 25, 2010 Accepted November 11, 2010)

\begin{abstract}
This paper presents a linear parameter estimation technique used to estimate the rotor resistance, self inductance of the rotor winding, stator resistance and the stator leakage inductance of an induction motor. Such estimation is important for achieving high estimation performance of induction motor drives. The parameters estimation model expresses the relationships of the dynamic machine model in terms of measurable stator voltages, currents and motor speed. This model is represented by a linear regression equation from which machine parameters can be obtained using a recursive least squares $(\boldsymbol{R L S})$ estimation algorithm. Simulation results are presented to validate the proposed estimation algorithm with reasonable accuracy of the estimated parameters regardless of load conditions. Comparisons between experimental and calculated steady-state performances using the estimated parameters are also presented.
\end{abstract}

KEYWORDS: Parameters estimation, Induction motor, Recursive Least Squares.

\section{INTRODUCTION}

The induction motors has been gradually replacing the DC motors in many applications due to reliability, ruggedness and relatively low cost. The control and estimation of induction motor drives in general are considerably more complex than those of DC motor drives and this complexity increases substantially if high performances are demanded [1]. Most modern induction machine drives use vector control strategies. These strategies require knowing the position of any of the motor magnetic fluxes (rotor, stator or magnetising) to operate properly. In practical applications, these fluxes are not directly measured, instead they are computed using estimators or state observers [2]. Moreover, many drives use methods to estimate other motor variables, such as rotor speed [3] or phase currents [4]. These methods are generally based on an equivalent electric circuit, which has different parameters for each particular machine. When incorrect parameter values are used in the controller, it may cause instantaneous errors in both torque and flux estimation, resulting in sluggish dynamics. 


\begin{tabular}{|c|c|c|c|}
\hline \multicolumn{4}{|c|}{ NOMENCLATURE } \\
\hline$i_{\alpha s}$ and $i_{\beta s}$ & $\alpha$ - and $\beta$-axis stator currents & $R_{s}$ and $R_{r}$ & $\begin{array}{l}\text { stator and rotor circuit } \\
\text { resistances }\end{array}$ \\
\hline$i_{\alpha r}$ and $i_{\beta r}$ & $\alpha$ - and $\beta$-axis rotor currents & $T_{e}$ and $T_{l}$ & $\begin{array}{l}\text { electromagnetic motor and } \\
\text { load torques }\end{array}$ \\
\hline$i_{s}$ and $i_{r}$ & $\begin{array}{l}\text { stator and rotor currents } \\
\text { space vectors }\end{array}$ & $V_{s}$ & stator voltage space vector \\
\hline$J$ & Total moment of inertia & $V_{\alpha s}$ and $V_{\beta s}$ & $\begin{array}{l}\alpha \text { - and } \beta \text {-axis stator } \\
\text { voltages }\end{array}$ \\
\hline$j$ & $\begin{array}{l}\text { represents the standard } \\
\sqrt{-1} \text { complex number }\end{array}$ & $\lambda_{s}$ and $\lambda_{r}$ & $\begin{array}{l}\text { stator and rotor flux space } \\
\text { vectors }\end{array}$ \\
\hline$L_{s}$ and $L_{r}$ & $\begin{array}{l}\text { stator and rotor self } \\
\text { inductances }\end{array}$ & $\omega_{r}$ & $\begin{array}{l}\text { electrical rotor angular } \\
\text { speed }\end{array}$ \\
\hline$L_{l s}$ and $L_{l r}$ & $\begin{array}{l}\text { stator and rotor leakage } \\
\text { inductances }\end{array}$ & $\omega_{m}$ & $\begin{array}{l}\text { mechanical rotor angular } \\
\text { speed }\end{array}$ \\
\hline$L_{m}$ & mutual inductance & $\omega_{s}$ & synchronous angular speed \\
\hline$p$ & number of pair poles & $\wedge$ & denotes the estimated value \\
\hline
\end{tabular}

Traditionally, the equivalent circuit parameters are measured by performing three well-known tests [5]. These tests are the DC test, the no-load test and the lockedrotor test. These off-line methods are very simple but extremely approximative. However, in many industrial fields, it is very difficult to perform these tests because the machine is usually coupled to the mechanical load. The machine service must be interrupted while these testes are performed. This is in addition to the difficulty to perform the locked rotor test on large power machines. Moreover, under the locked rotor test at rated frequency, the skin effect can heavily influence the accuracy of the rotor circuit resistance. Thus, they can lead to inadequate operating conditions and inaccurate parameter estimation. In [6] a review of numerous methods being proposed to identify the motor parameters is introduced. In most of these methods, only one parameter (rotor time constant or resistance) estimation is considered. Recently, rotor resistance tuning for indirect stator flux oriented induction motor drive based on model reference adaptive system (MRAS) is proposed in [7], but this method requires special test equipments and extensive test procedures.

In [8-9] an extended Kalman filter (EKF) has been used for parameter estimation. The major problems related to EKF applications are computational intensity and the fact that all the inductances are treated as constants in the motor equations. The time-domain and frequency-domain tests have been proposed in [10] and [11] for estimating the induction machine parameters. They might be expensive to perform, require special test equipment, and have a low sensitivity to detuning. In addition, some of them simplify the problem by assuming that all the other parameters are exactly known, except the parameter under consideration.

More recently different approaches like neural networks [12] and fuzzy estimators [13] have also been investigated to estimate induction motor parameters but these methods require greater computational burden. Again, there is a lack of extensive experimental results, which are the only way to demonstrate the stability of those 
systems. While the MRAS based estimators are preferred because of their simplicity, ease of implementation and their proven stability [14]. They have a certain disadvantage in the low-speed area, where open-loop integration may lead to instability due to stator resistance and leakage inductance as well as rotor circuit parameters. In [15] the least-square (LS) procedure has been applied in an original way to obtain an estimate of the stator and rotor resistances and self reactances, but exposed method is not strictly recursive. All of this has limited the application of high performance induction motor drives.

This paper presents a model and a procedure used to estimate most of electrical parameters of an induction motor. These parameters are namely, the rotor resistance, self inductance of the rotor winding, stator resistance and the stator leakage inductance. Such estimation is important for achieving high performance of induction motor drives. The presented model is derived from the dynamic machine model. This model is represented by a linear regression equation from which machine parameters can be obtained using the recursive least squares (RLS) estimation algorithm. The estimation algorithm provides good estimation accuracy of parameters at any load conditions. Simulation results are presented which demonstrate the effectiveness of the proposed estimation algorithm. The validity of the proposed estimation algorithm is checked by comparing the calculated steady-state performances using estimated parameters with those obtained experimentally.

\section{INDUCTION MOTOR MODELS}

\subsection{Steady-State Model}

The steady-state motor model can be deduced from the description of the stator and rotor electrical circuits. With this physical approach, five electrical elements are defined as the stator and rotor resistances $\left(R_{s}\right.$ and $\left.R_{r}\right)$, stator and rotor leakage inductances $\left(L_{l s}\right.$ and $\left.L_{l r}\right)$ and a magnetizing inductance $\left(L_{m}\right)$. This definition leads to the equivalent circuit for steady-state operation of an induction motor [16]. From this equivalent circuit, one can obtain an expression for the motor torque, stator current, input power factor and motor efficiency [16].

\subsection{Dynamic Model of an Induction Motor}

The dynamic model of an induction motor in a stationary axes reference frame $(\alpha-\beta)$ can be described as [17].

$$
\begin{gathered}
V_{s}=R_{s} i_{s}+\frac{d \lambda_{s}}{d t} \\
V_{r}=0=R_{r} i_{r}+\frac{d \lambda_{r}}{d t}-j \omega_{r} \lambda_{r}
\end{gathered}
$$

Stator and rotor flux linkages can be expressed as:

$$
\left\{\begin{array}{l}
\lambda_{s}=L_{s} i_{s}+L_{m} i_{r} \\
\lambda_{r}=L_{r} i_{r}+L_{m} i_{s}
\end{array}\right.
$$

Where 


$$
\left\{\begin{array}{l}
L_{s}=L_{l s}+L_{m} \\
L_{r}=L_{l r}+L_{m}
\end{array}\right.
$$

The stator and rotor currents space vectors and stator voltage space vector can be written in terms of their components as:

$$
\begin{gathered}
i_{s}=i_{\alpha s}+j i_{\beta s} \\
i_{r}=i_{\alpha r}+j i_{\beta r} \\
V_{s}=V_{\alpha s}+j V_{\beta s}
\end{gathered}
$$

The motor electromagnetic torque in terms of stator and rotor currents components is given as:

$$
T_{e}=\frac{3}{2} p L_{m}\left(i_{\beta s} i_{\alpha r}-i_{\alpha s} i_{\beta r}\right)
$$

The mechanical equation of the motor neglecting friction losses is given by

$$
T_{e}-T_{l}=J \frac{d \omega_{m}}{d t}
$$

Where $\omega_{m}=\frac{\omega_{r}}{p}$

\section{PARAMETER ESTIMATION BASED ON RLS ALGORITHM}

Standard methods for parameter estimation are based on equalities where known signals depend linearly on unknown parameters. However, the induction motor model described above does not fit in this category unless the rotor flux linkages are measured.

A modified model of an induction motor independent of rotor flux is obtained if one chooses a null rotor leakage inductance. Therefore, the parameters to be identified are rotor resistance, rotor self inductance, stator resistance and stator leakage inductance.

Introducing $L_{s}$ and $L_{r}$ in the time derivative of equation (3) to obtain the equation

$$
\frac{d \lambda_{s}}{d t}=L_{l s} \frac{d i_{s}}{d t}+\frac{d \lambda_{r}}{d t}
$$

Eliminating the rotor current, using equation (6) with equations (1) and (2) yields

$$
\begin{gathered}
V_{s}=L_{l s} \frac{d i_{s}}{d t}+R_{s} i_{s}+\frac{d \lambda_{r}}{d t} \\
V_{r}=0=\frac{R_{r}}{L_{r}} \lambda_{r}-R_{r} i_{s}+\frac{d \lambda_{r}}{d t}-j \omega_{r} \lambda_{r}
\end{gathered}
$$

Calculating the time derivatives of the difference between equations (7) and (8), the following equation can be obtained

$$
L_{l s} \frac{d^{2} i_{s}}{d t^{2}}=-\left(R_{s}+R_{r}\right) \frac{d i_{s}}{d t}+\left(\frac{R_{r}}{L_{r}}-j \omega_{r}\right) \frac{d \lambda_{r}}{d t}-j \frac{d \omega_{r}}{d t} \lambda_{r}+\frac{d V_{s}}{d t}
$$


Making the product of $\left(\frac{R_{r}}{L_{r}}-j \omega_{r}\right)$ and the difference between equations (7) and (8), this produces

$$
\left(\frac{R_{r}}{L_{r}}-j \omega_{r}\right) L_{l s} \frac{d i_{s}}{d t}=\left(\frac{R_{r}}{L_{r}}-j \omega_{r}\right)\left(-\left(R_{s}+R_{r}\right) i_{s}+\left(\frac{R_{r}}{L_{r}}-j \omega_{r}\right) \lambda_{r}+V_{s}\right)
$$

Introducing equation (8) in the sum of equations (9) and (10) to eliminate the time derivatives of rotor flux yields:

$$
\begin{aligned}
\left(\frac{R_{r}}{L_{r}}-j \omega_{r}\right) L_{l s} \frac{d i_{s}}{d t}+L_{l s} \frac{d^{2} i_{s}}{d t^{2}} & =-\left(R_{s}+R_{r}\right) \frac{d i_{s}}{d t}+\left(\frac{R_{r}}{L_{r}}-j \omega_{r}\right) R_{r} i_{s} \\
- & \left(\frac{R_{r}}{L_{r}}-j \omega_{r}\right)\left(R_{s}+R_{r}\right) i_{s}+\frac{d V_{s}}{d t} \\
& +\left(\frac{R_{r}}{L_{r}}-j \omega_{r}\right) V_{s}-j \frac{d \omega_{r}}{d t} \lambda_{r}
\end{aligned}
$$

After some algebraic manipulations, equation (11) can be rewritten as:

$$
\begin{aligned}
\frac{d^{2} i_{s}}{d t^{2}}-j \omega_{r} \frac{d i_{s}}{d t}+j \frac{\left(d \omega_{r} / d t\right)}{L_{l s}} & \lambda_{r}=-\left(\frac{R_{r}}{L_{r}}+\frac{R_{r}+R_{s}}{L_{l s}}\right) \frac{d i_{s}}{d t}-\frac{R_{r} R_{s}}{L_{l s} L_{r}} i_{s}+j \frac{R_{s}}{L_{l s}} \omega_{r} i_{s} \\
+ & \frac{1}{L_{l s}}\left(\frac{d V_{s}}{d t}-j \omega_{r} V_{s}\right)+\frac{R_{r}}{L_{l s} L_{r}} V_{s}
\end{aligned}
$$

The use of RLS estimation techniques requires that the system model (equation 12) is to be defined as a regression equation in the form

$$
y(t)=x(t) \theta
$$

Where $y(t), x(t)$ and $\theta$ are the prediction vector, the regression matrix and the parameters vector, respectively.

During the identification process the motor speed is assumed to be constant $\left(\frac{d \omega_{r}}{d t}=0\right)$, then equation (12) can be rewritten as:

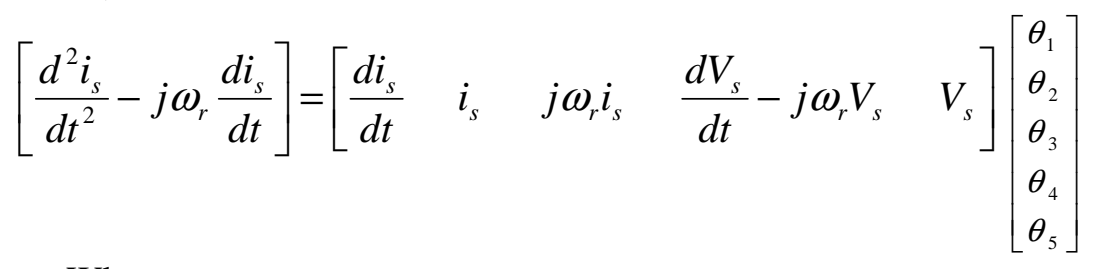

Where

$$
\begin{aligned}
& y(t)=\frac{d^{2} i_{s}}{d t^{2}}-j \omega_{r} \frac{d i_{s}}{d t} \\
& x(t)=\left[\begin{array}{lllll}
\frac{d i_{s}}{d t} & i_{s} & j \omega_{r} i_{s} & \frac{d V_{s}}{d t}-j \omega_{r} V_{s} & V_{s}
\end{array}\right]
\end{aligned}
$$




$$
\begin{aligned}
& \theta_{1}=-\frac{R_{r}}{L_{r}}-\frac{R_{r}+R_{s}}{L_{l s}} \\
& \theta_{2}=-\frac{R_{r} R_{s}}{L_{l s} L_{r}} \\
& \theta_{3}=\frac{R_{s}}{L_{l s}} \\
& \theta_{4}=\frac{1}{L_{l s}} \\
& \theta_{5}=\frac{R_{r}}{L_{l s} L_{r}}
\end{aligned}
$$

The following steps describe the RLS algorithm used to estimate the unknown vector $\hat{\theta}$.

1. Initial conditions: The initial value of the estimated parameter vector $\hat{\theta}$ is set equal to zero. The initial covariance matrix $P$ is assumed to be a diagonal matrix with large positive numbers.

2. Compute estimate $\hat{y}$

$$
\hat{y}(t)=x(t) \hat{\theta}(t-1) \text {. }
$$

3. Compute the estimation error of $y(t)$

$$
\varepsilon(t)=y(t)-\hat{y}(t) \text {. }
$$

4. Compute the estimation covariance matrix $P$ at instant $t$

$$
P(t)=P(t-1)-\frac{P(t-1) x^{T}(t) x(t) P(t-1)}{\alpha+x(t) P(t-1) x^{T}(t)}
$$

The forgetting factor $\alpha$ is used in this algorithm to track the time variation of the unknown parameters.

5. Compute the estimation vector $\hat{\theta}$ at instant $t$

$$
\hat{\theta}(t)=\hat{\theta}(t-1)+P(t) x(t) \mathcal{E}(t) .
$$

Continues the updating process until a weighted quadratic cost function $(G)$ is minimized for $N$ successive instants samples:

$$
G=\sum_{i=1}^{N}|y(t)-x(t) \hat{\theta}(t)|^{2}
$$

By estimating vector $\hat{\theta}$, the induction motor parameters can easily be deduced by using the following equations:

$$
\begin{gathered}
\hat{R}_{s}=\frac{\hat{\theta}_{3}}{\hat{\theta}_{4}} \\
\hat{L}_{l s}=\frac{1}{\hat{\theta}_{4}}
\end{gathered}
$$




$$
\begin{aligned}
& \hat{L}_{r}=\frac{1}{\hat{\theta}_{5}}\left(\frac{\hat{\theta}_{1}}{\hat{\theta}_{3}}-\hat{\theta}_{1}-\hat{\theta}_{3}\right) \\
& \hat{R}_{r}=\frac{1}{\hat{\theta}_{4}}\left(\frac{\hat{\theta}_{2}}{\hat{\theta}_{3}}-\hat{\theta}_{1}-\hat{\theta}_{3}\right)
\end{aligned}
$$

\section{SIMULATION, EXPERIMENTAL RESULTS AND DISCUSSIONS}

In order to verify the validity and the performance of the proposed procedure a computer simulations using MATLAB software and experimental work have been carried out. The tested motor was a $9.8 \mathrm{HP}, 220 \mathrm{~V}, 50 \mathrm{~Hz}$, delta connection, slip-ring induction motor. The rated stator current per phase was $15.1 \mathrm{~A}$ at $1450 \mathrm{rpm}$. Coupled to the motor was a DC generator of about the same rating. The equivalent circuit parameters for it have been determined by tests given in [5].

The parameter estimation procedure is carried out using the presented regression equation (equation 14) and the RLS algorithm with forgetting factor. The machine is to be supplied by a balanced three phase sinusoidal voltage source. The parameter estimation algorithm runs with the data obtained by digital simulation.

Table 1 illustrates the estimated values of electrical motor parameters obtained using the RLS algorithm and those obtained experimentally (standard tests). The third row shows the percentage error results. It can be noted that the estimation algorithm is able to estimate most of the electrical machine parameters with good precision (estimation errors between $2-4 \%$ ). These errors are small and acceptable to get good parameter estimation.

Table 1: Estimated and standard induction motor parameters

\begin{tabular}{|c|c|c|c|c|}
\hline Electrical Machine Parameters & $R_{r}(\Omega)$ & $R_{s}(\Omega)$ & $L_{l s}($ Henry $)$ & $L_{r}($ Henry $)$ \\
\hline Experimentally & 0.174 & 0.512 & 0.0051 & 0.1122 \\
\hline Using RLS algorithm & 0.1701 & 0.5061 & 0.0053 & 0.1154 \\
\hline$\%$ | Error | & $2.241 \%$ & $1.152 \%$ & $3.922 \%$ & $2.852 \%$ \\
\hline
\end{tabular}

Figure 1 shows the simulation results for stator resistance estimation values. From this figure, it can be seen that the estimate converge quickly to the measured one with limited estimation errors in steady-state.

Figure 2 shows the simulation results for stator leakage inductance estimation values. From this figure it can be noted that the initial high transient peak (about 0.58 $\mathrm{H})$ is due to the startup of the RLS algorithm and the estimate track very well to the measured one. Figure 3 shows the simulation results for rotor self inductance estimation values. This figure provides fast convergence time and small estimation errors in steady-state. 
Figure 4 shows the simulation results for rotor circuit resistance estimation values. From this figure, it can be seen that the rotor circuit resistance converge some what slowly to the measured one and provide small estimation errors in steady-state.

It can be seen from these figures 1-4 that the different estimated parameters follow the real ones very closely, which indicates that the proposed identification procedure works successfully for induction motor parameters estimation.

The validity of the presented method of estimating induction motor parameters is checked by comparing the calculated steady-state performance characteristics using estimated parameters with those measured experimentally when the source voltage and frequency are maintained at their rated values.

Figure 5 shows that calculated, estimated and experimental values of the motor per-unit speed versus motor torque. From this figure, it can be noted that the estimated values of motor speed and measured one have small deviation. The discrepancy between calculated, estimated and measured speed values, especially at high values of motor torque, is attributed to the mechanical loss which is disregarded from the equivalent circuit.

Figures 6 and 7 show the estimated and experimental values of stator current and input power factor. These figures indicate that, the estimated values are well matched and agree with their measured ones. On the other hand, large deviation between the calculated values of stator current and input power factor and their measured ones are due to the fact that the machine parameters values are assumed to be constant at all operating conditions.

From these figures 5 to 7 it can be seen that, the using of the estimated parameter provides good performance characteristics of induction motor, which indicates that the presented estimation procedure works successfully for motor parameter estimation.

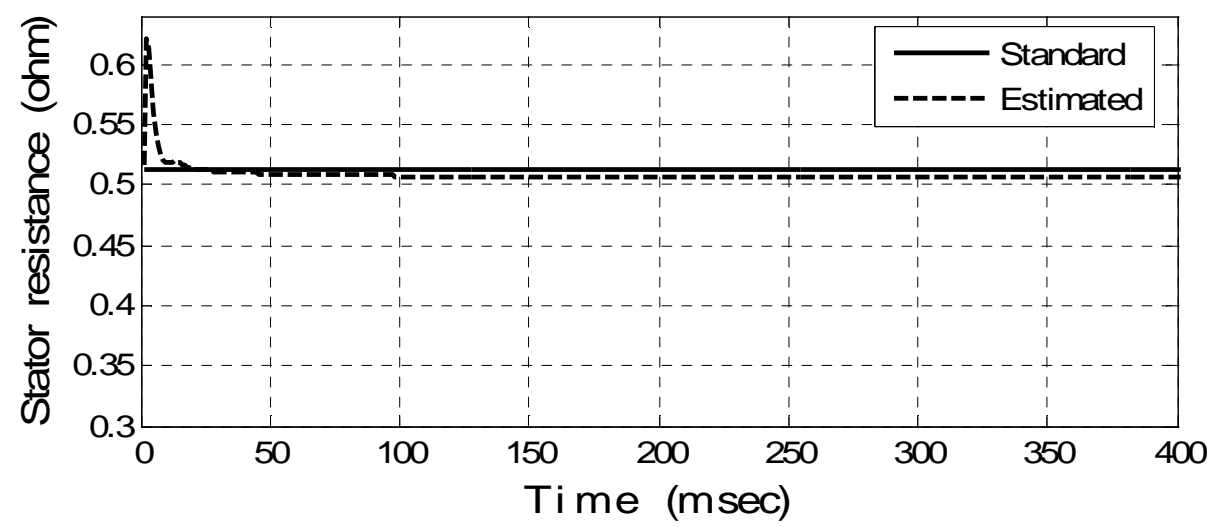

Figure 1: Standard and Estimated values of stator resistance 


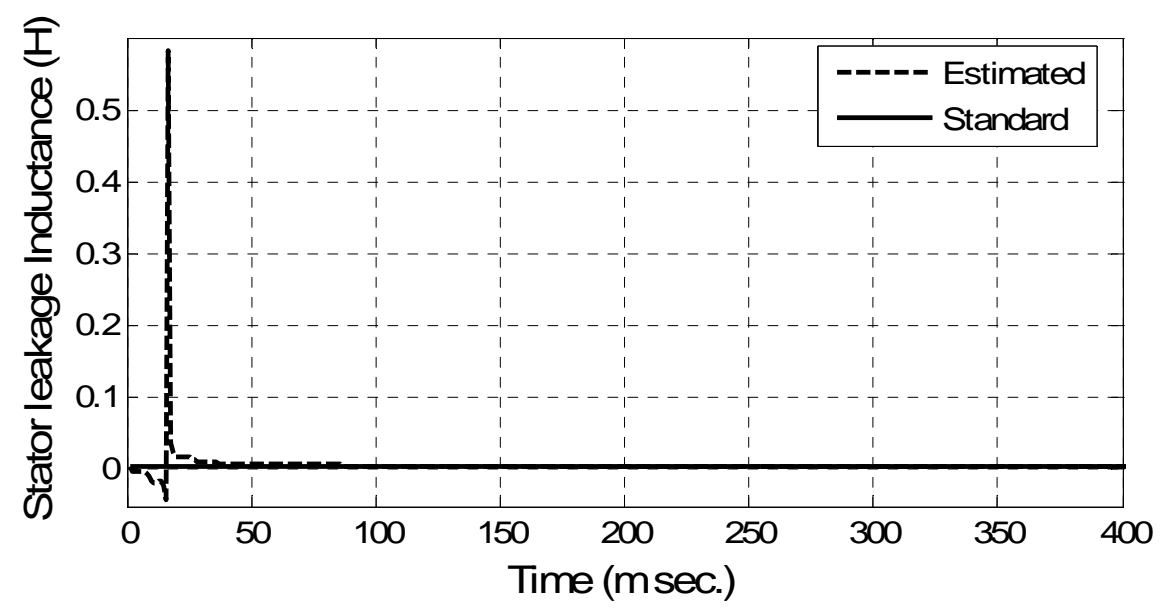

Figure 2: Standard and Estimated values of stator leakage inductance

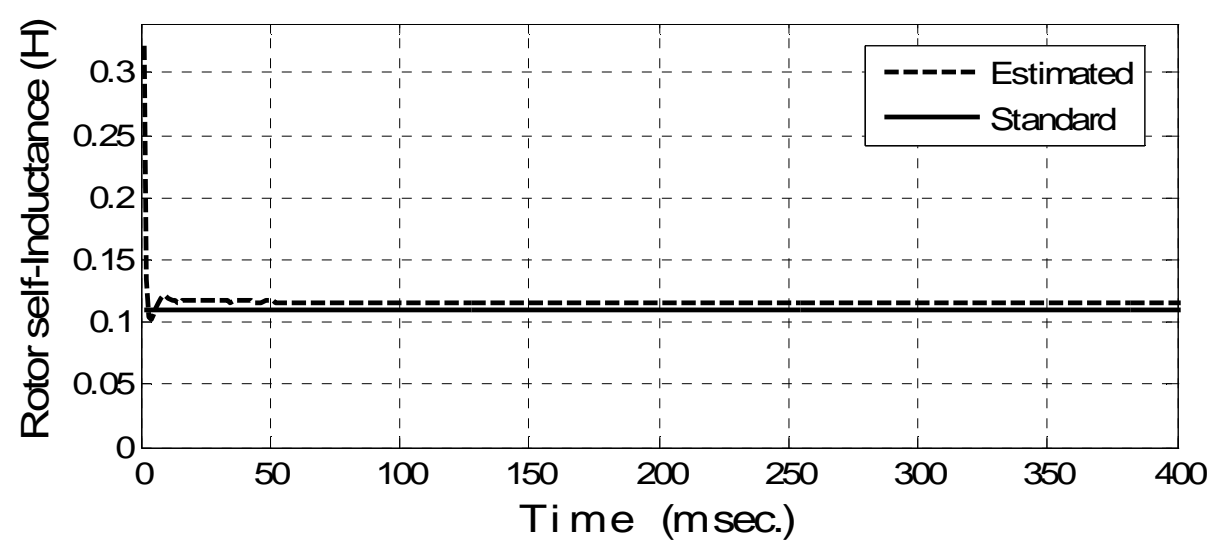

Figure 3: Standard and Estimated values of rotor inductance

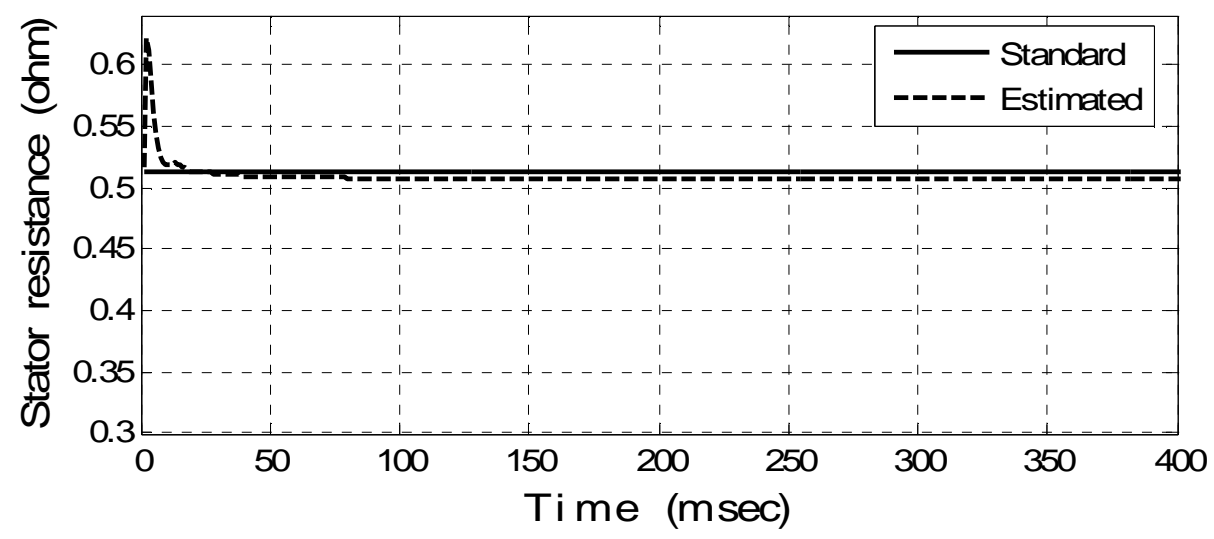

Figure 4: Standard and Estimated values of rotor resistance 


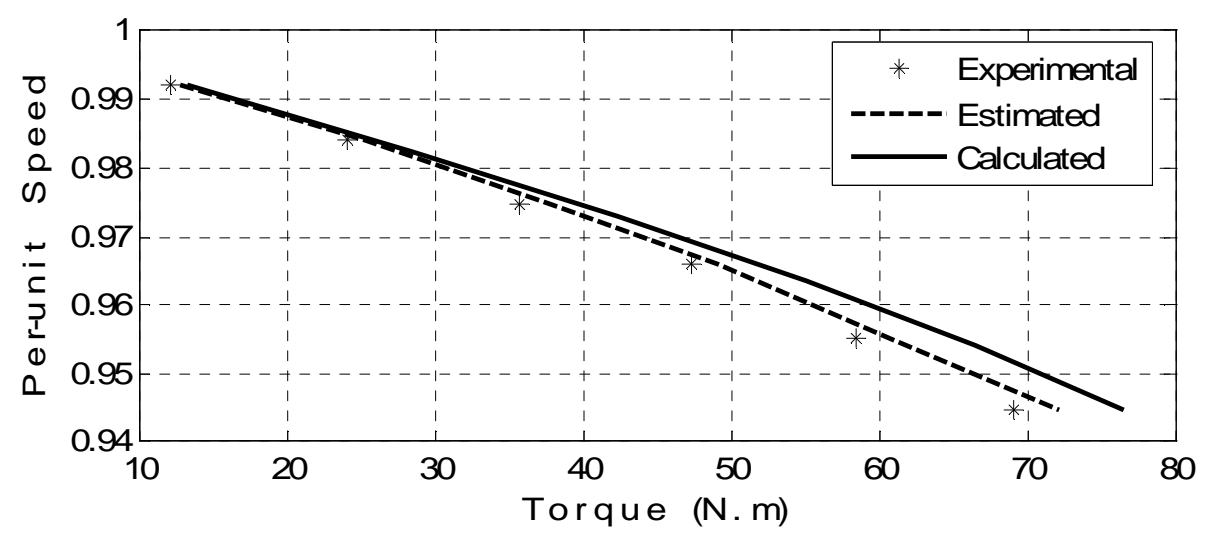

Figure 5: Speed-Torque characteristics of induction motor

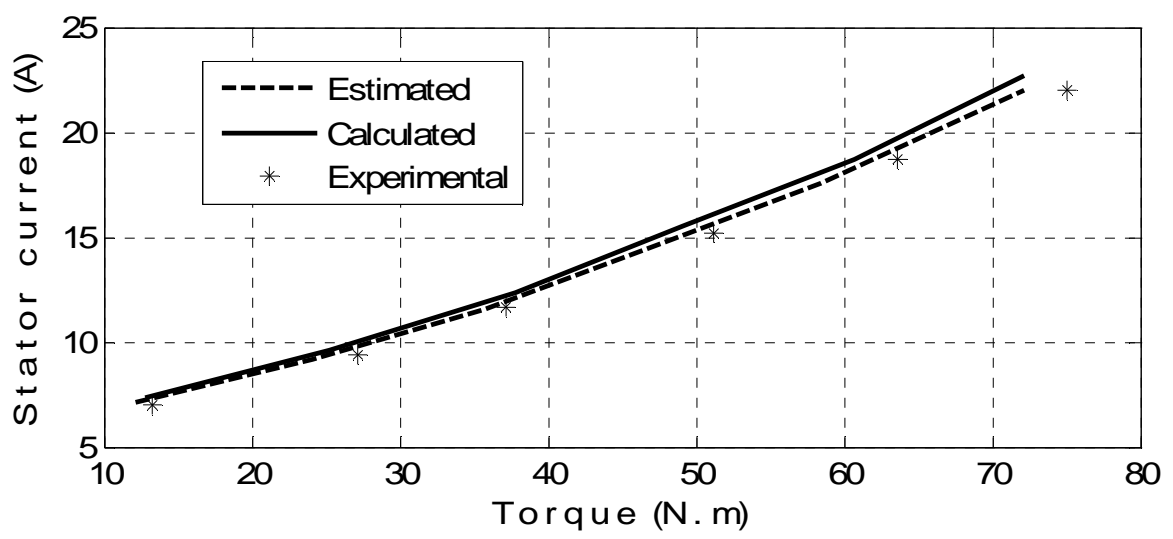

Figure 6: Stator current versus torque characteristics of induction

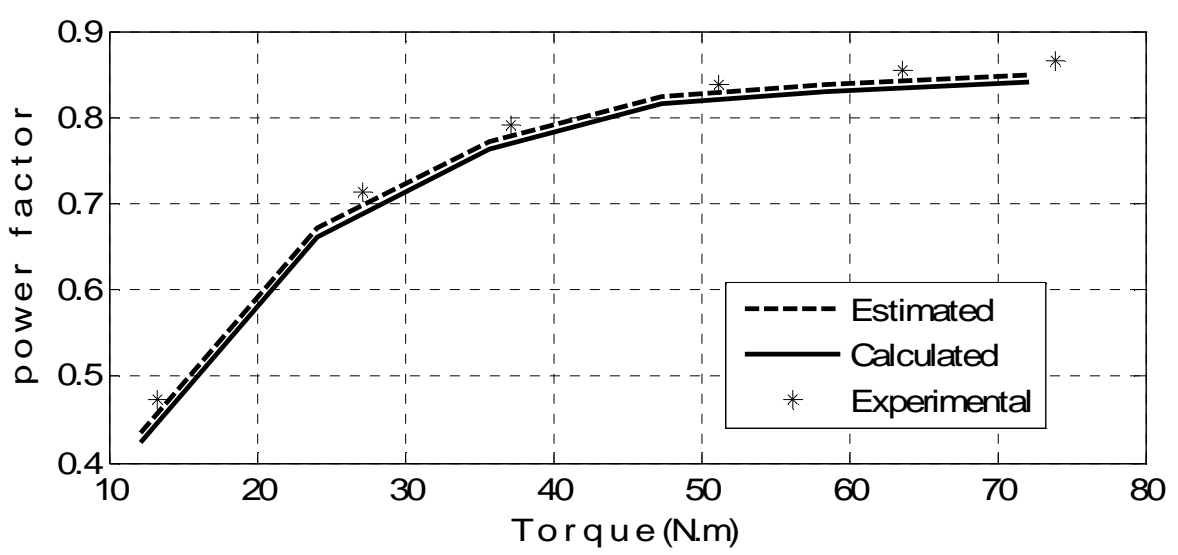

Figure 7: Power factor versus torque characteristics of induction 


\section{CONCLUSION}

An identification methodology based on the RLS algorithm was successfully applied in this work to identify most of the electrical parameters of an induction motor using the measurable stator currents and voltages at constant speed. The estimation model takes the form of the linear regression equation which is derived from the dynamical machine model. The identification algorithm should be executed when the system is in steady state operation. The accuracy of the estimated parameters using the proposed technique is in reasonable agreement with those obtained experimentally. It can be seen from the experimental results that the performance characteristics which are obtained using estimated parameters follow the experimental ones very closely. This indicates that the proposed identification procedure works successfully for induction motor parameters estimation. From the present analysis, one can draw the following main conclusions:

1. The presented regression model has provided good estimation accuracy regardless of load condition

2. The estimated parameters $\left(R_{s}, R_{r}, L_{l s}\right.$ and $\left.L_{r}\right)$ have provided good performances, i.e. fast convergence time and track well their measured ones with small estimation errors.

3. Good agreements between experimental and calculated steady-state performances using the estimated parameters demonstrate the effectiveness of the proposed identification algorithm.

\section{REFERENCES}

1. M.R. Rashmi, S. Rajapndian and S. Devegowda, "Parameter Tuning Improved

2. Dynamic Response of Indirect Stator Flux Oriented Induction Motor Drives", International Journal of Electrical and Power Engineering, 3 (3), 169-174, 2009.

3. Verghese, G.C., and Sanders, S.T.: 'Observers for flux estimation in induction machines', IEEE Trans. Ind. Electron., 1998, 35, (1), pp. 85-94

4. Kubota, H., Matsuse, K., and Nakano, T.: 'DSP-based speed adaptive flux observer of induction motor', IEEE Trans. Ind. Appl., 1993, 29, pp. 344-348

5. Sonnaillon, M.O., Bisheimer, G., Angelo, De, Solsona, J., and Garcia, G.O.: "Mechanical-sensorless induction motor drive based only on DC-link measurements", IEE Proc. Electr. Power Appl., 2006, 153, (6), pp. 815-822

6. IEEE Standard 112-1991, "IEEE Standard Test Procedure for Polyphase Induction Motors and Generators," Institute of Electrical and Electronics Engineers, Inc.

7. H. A. Toliyat, E. Levi, M. Raina, "A Review of RFO Induction Motor Parameter Estimation Techniques", IEEE Trans. On Energy Convwersion, Vol. 18, No. 2, pp. 271-283, 2003.

8. Y. Koubaa, M. Boussak, , "Rotor resistance tuning for indirect stator flux oriented induction motor drive based on MRAS scheme", Eur. Trans. Electr. Power (ETEP), 15 (4), 557-570, 2005. 
9. L. C. Zai, C. L. DeMarco, and T. A. Lipo, "An extended Kalman fliter approach to rotor time constant measurement in pwm induction motor drives," IEEE Trans. Ind. Applicat., vol. 28, pp. 96-104, Jan./Feb. 1992.

10. L. Loron and G. Laliberte, "Application of the extended Kalman fliter to parameters estimation of induction motors," inProc. Europe. Conf. Power Electron. Applicat., vol. 5, pp. 85-90, 1993.

11. S. I. Moon and A. Keyhani, "A estimation of induction machine parameters from standstill time-domain data," IEEE Trans. Ind. Applicat., vol. 30, pp. 1609-1615, Nov./Dec. 1994.

12. J. K. Seok, S. I. Moon, and S. K. Sul, "A induction machine parameter identification using PWM inverter at standstill," IEEE Trans. Energy Conversion, vol. 12, pp. 127-132, June 1997.

13. Mustafa AKTAS and H. Ibrahim OKUMUS, "Stator resistance estimation using ANN in DTC IM drives", Turk J Elec Eng \& Comp Sci, Vol.18, No.2, 2010.

14. Dinko Vukadinovic, Mateo Basic and Ljubomir Kulisic, "Stator resistance identification based on neural and fuzzy logic principles in an induction motor drive" Neurocomputing, Elsevier, 73 (2010) 602-612.

15. R. Blasco-Gimenez, G. Asher, M. Summer, and K. Bradley, "Dynamic Performance Limitations for MRAS Based Sensorless Induction Motor Drives. Part 1: Stability Analysis for the Closed Loop Drive", Proc. IEE-Elect. Power Applicat., Vol. 143, PP. 113-122, Mar. 1996.

16. Holtez, J. and Thimm, T. "identification of the machine parameter in a vectorcontrolled induction motor drive", IEEE Transaction on Industry Applications, 27(6), pp. 1111-1118. 1991.

17. M. Liwschitz-Garik and C. C. Whipple, 1961, "Alternating-Current Machines", Van Nostrand.

18. D.W. Novotny, T.A. Lipo, "Vector Control and Dynamics of AC Drives", Clarendon, New York, 1996.

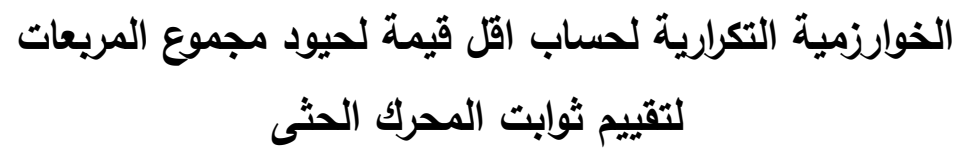

هذا البحث يقدم طريقة خطية لتقييم كلاً من مقاومة العضو الدوار والحث الذاتى لملفات العضو الدوار ومقاومة العضو الثابت وكذلك الحث المنسرب للعضو الثابت لمحرك حثى. ويمثل هذا التقييم للثوابت المذكورة أهمية كبرى للحصول على أداء عالى من نظام التحكم للمحرك الحث.

تم عمل نموذج لتقييم الثوابت يعبر عن العلاقة بين النموذج الديناميكى للمحرك وقيم الجهود والتيارات المقاسـة لدائرة العضـو الثابـت وكذلك سـرعة المحرك المقاسـة. هذا النمـوذج يمكن تمثيله بواسطة معادلـة خطيـة وذلك للحصول على ثوابت الماكينة وذلك باستخدام الطريقة التكراريـة لحساب اقل قيمة لحيود مجموع المربعات. وقد أنتبت النتائج المطروحة الدقة المرضية لتقييم الثوابت دون النظر لقيمة الحمل. تم أيضا تقديم مقارنات بين النتائج العملية والمحسوبة باستخدام الثوابت المقدرة لمعدلات الأداء فى حالة الاستقرار . 
